\title{
Heat integration applied on low thermal energy system: Building complex case study
}

\author{
Ibaaz Khalid ${ }^{1, *}$, Cherkaoui Moha ${ }^{2}$, Cherkaoui Mohamed ${ }^{1}$, and Annaba Khadija ${ }^{3}$ \\ ${ }^{1}$ Engineering for Smart and Sustainable Systems Research Centre, Mohammadia School of Engineering, Mohamed V University in \\ Rabat, Morocco \\ ${ }^{2}$ Renewable Energy and Energy efficiency Laboratory, National School of Mines-Rabat, Morocco \\ ${ }^{3}$ Civil Engineering and construction, Mohammadia School of Engineers, Mohamed V University in Rabat,
}

\begin{abstract}
The tertiary-building sector is one of the most important energy consumers in the Morocco, especially thermal energy. Its intensive use of energy is highly related to the building's inefficient processes. The Moroccan strategy for energy efficiency aims mainly to save $12 \%$ of energy consumption by 2020 and $15 \%$ by 2030 , which reinforce the appearance of many energy saving alternatives ranging from sensitization and construction laws to engineering applications. The present paper addresses the problem of the building complex energy efficiency in order to improve its performance thermally. The proposed approach in this work is based on the pinch technology which is a technique widely used to integrate and optimize the energy of thermal systems and which has demonstrated its successfulness for industrial process. The simulation results reveals that the potential thermal energy saving reaches $21.16 \%$, with heat exchange network design initially proposed to clearly show the potential recovered. Based on the composite curves (CCs), the problem table algorithm (PTA) and the grand composite curve (GCC), the pinch point temperature is turned out to be $15^{\circ} \mathrm{C}$ with $316,99 \mathrm{~kW}$ of hot utility. The obtained results reveal that the proposed pinch technology perform its effectiveness not only in the industrial sector but also in the building-tertiary.
\end{abstract}

\section{Introduction}

Doubling the global rate of enhancement in Energy Efficiency is one of the most important objectives of Sustainable Energy for All; an initiative launched by the United Nations [1]. Many governments have oriented their transition strategies towards more sustainable and affordable energy systems. As an example, Morocco has established its own National Energy Strategy (NES) in 2009. Part of this strategy was the adoption of several orientations; primarily the rise of renewable energies and energy efficiency [2-3]. Renewable energies and energy efficiency (EE) are the two main pathways towards Morocco's energy independence as well as the real and effective contribution of the Kingdom to the efforts of the international community to maintain global warming below $2{ }^{\circ} \mathrm{C}$ [4].

Aside from the basic known definition of energy efficiency (EE), it is considered to be a fourth source of energy after the fossil, nuclear and renewable energy. EE concerns different sectors of activity: residential-tertiary, transport, industry and agriculture. In Morocco, the building sector is one of the largest consumers of energy with a share of about $33 \%$ of the overall energy consumption of the country [5]. Their huge utilization of energy is the reason for the appearance of many studies about energy saving alternatives. There are two main types of building energy efficiency: passive energy efficiency and active energy efficiency. The passive energy efficiency on the one hand concerns insulation, heating equipment and ventilation. D. D'Agostino et al. [6] have evaluated under dynamic conditions the energetic and economic influence of external thermal insulation by using energy simulations. M. Jerman et al. [7] have investigated thermal and hygric properties of several biomaterials potentially applicable as thermal insulation boards on the interior side of historical building envelopes. According to the work of El Khattabi et al. [8] in which they studied and analyzed the smart windows in typical building design, the natural optimization of thermal comfort in winter and summer can be reached by using such windows composed by special materials. Characterized by their phase transition, the materials makes sure that the transmission coefficient is lower for high temperature and higher for low one.

On the other hand, active energy efficiency refers to regulation, building management and energy management including heat recovery. The production and efficient use of thermal energy in the building sector is a major concern for managers. In fact, the heating and cooling needs are satisfied using several utilities. As an example, for a tertiary building that consists of $\mathrm{N}$ rooms, $\mathrm{N}$ showers, hot water for cooking and laundry, boiler, ventilation, industrial cold, heat production by CSP, etc ... an energy optimization system allows to serve all components of the building through a heat exchange

*orresponding author: ibaaz.khalid@gmail.com 
network dimensioned carefully. This reduces energy consumption by recovering the wasted heat of the building. Such a method of energy optimization is called "Pinch Analysis (PA)".

PA was firstly developed by B. Linnhoff and J. Flower [9]. It provides a practical and systematic approach for process optimization [10-11]. Due to its simplicity, it is widely applied to optimize various industrial processes [12]. Many works have been done in order to investigate the role of PA in the building sector. A. Bertrand et al. [13] proposed the pinch method to quantify the buildingspecific energy cost and energy saving potentials. The method was applied at the urban scale of in-building waste water heat recovery systems. The same method has been adopted and applied in [14] to evaluate the energy saving at a low enthalpy thermal system. V. Miseviciute and al. [15] have analyzed the process integration possibilities in a ventilation system of a building, where they have confirmed that the efficiency of the ventilation system has increased in term of energy; the integrated system consumes less energy and exergy in comparison with the non-integrated ones. The literature review shows the universality and wide range of applications of the pinch technique as well as its intelligent and rigorous effectiveness in various sectors such as industry and building.

The main goal of this work is to evaluate the possibilities of applying the pinch method to building tertiary in order to define and improve their thermodynamic efficiency as well as to assess their potential energy savings.

\section{Methodology}

Pinch Analysis is the most complete and advanced «toolbox» for process energy integration based on thermodynamic concepts. The method used in this paper has therefore as fundamental points mass and energy balances. It is performed in several steps (fig. 1) to construct an energy efficient heat exchange network (HEN). Each step will be described in details through this case study.

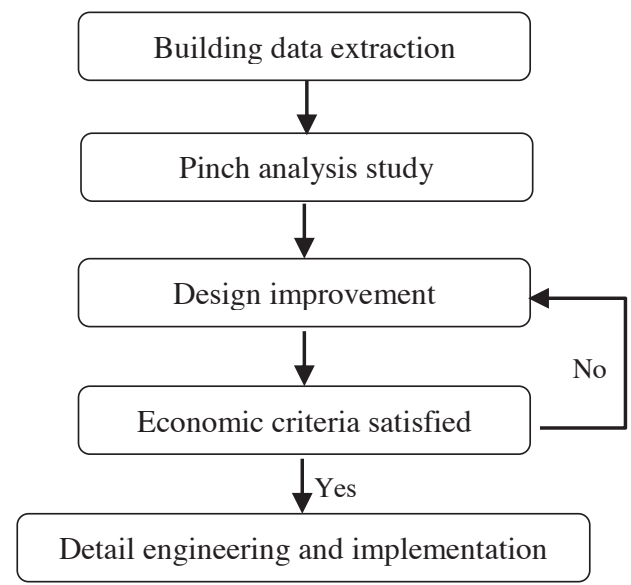

Fig. 1. The used method.

\subsection{Data extraction and streams identification}

The first step of the Pinch analysis is determining the existing streams of hot and cold heat transfer fluids. The hot and cold streams data are extracted from the building complex design flowsheet. The type of the stream is determined by its supply (initial) and target (final) temperatures. Fig. 2 shows the thermal system diagram of the building complex. The stream is considered to be hot if the supply temperature of the heat transfer fluid is higher than the final temperature; else it is considered to be cold. A hot stream means a stream that has to be cooled down; meanwhile a cold stream has to be heated up.

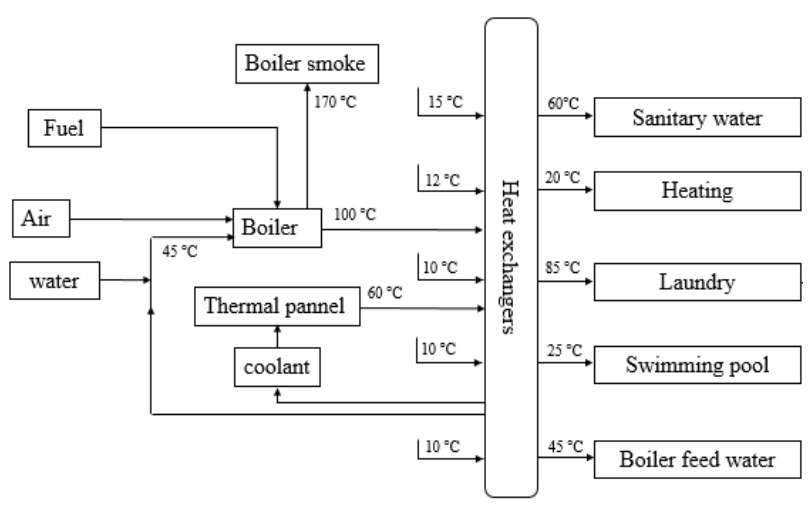

Fig. 2. Building complex thermal system diagram

The thermal demand in the building is covered by 2 boilers covering $320 \mathrm{~kW}$ using "Fuel" and 12 solar collector planes with no heat recovery network in the building complex. To apply the pinch method, the flow of the boiler's condensed smoke which is not recovered in the condensation network as well as the wasted heat from the soapy water of the laundry were identified as hot streams. Table 1 summarizes the results of heating and cooling streams of building complex extracted from mass and energy balance data.

Table 1. Setting Word's margins.

\begin{tabular}{|c|c|c|c|c|c|}
\hline $\mathbf{N}$ & type & $\mathbf{T}_{\mathbf{s}}\left({ }^{\circ} \mathbf{C}\right)$ & $\mathbf{T}_{\mathbf{t}}\left({ }^{\circ} \mathbf{C}\right)$ & $\begin{array}{c}\Delta \mathbf{H} \\
(\mathbf{k W})\end{array}$ & Name \\
\hline 1 & hot & 170 & 120 & 60,08 & $\begin{array}{c}\text { Boiler } \\
\text { smoke (BS) }\end{array}$ \\
\hline 2 & hot & 76 & 30 & 20,19 & $\begin{array}{c}\text { Soapy water } \\
\text { (Soa) }\end{array}$ \\
\hline 3 & cold & 10 & 85 & 67,31 & $\begin{array}{c}\text { Laundry } \\
(\mathrm{L})\end{array}$ \\
\hline 4 & cold & 15 & 60 & 85 & $\begin{array}{c}\text { Sanitary } \\
\text { water (SW) }\end{array}$ \\
\hline 5 & cold & 12 & 20 & 103.08 & $\begin{array}{c}\text { Heating } \\
(\mathrm{H})\end{array}$ \\
\hline 6 & cold & 10 & 25 & 131 & $\begin{array}{c}\text { Swimming } \\
\text { pool (SP) }\end{array}$ \\
\hline 7 & cold & 10 & 45 & 10,15 & $\begin{array}{c}\text { Boiler feed } \\
\text { water (BF) }\end{array}$ \\
\hline
\end{tabular}

\section{$2.2 \Delta \mathrm{T}_{\min }$ and the composites curves}

One the streams are determined and quantified in terms of temperature and heat load (table 1), the data is used to 
draw curves giving a meaning to our study. The composite curves are one of the main tools used in the Pinch analysis [9-11]; they represent the evolution of energy flows (hot and cold) in a diagram $(\mathrm{T}, \Delta \mathrm{H})$ i.e. the profile of available heat sources (hot composite curve) and the thermal requirements profile (cold composite curve) of the building complex. The CCs are used to establish the minimum energy consumption target values of a process.

After drawing the curves separately, the cold composite curve is positioned on the same diagram with the hot composite curve (fig. 3) in order to establish the target values of minimum energy consumption. The cold composite curve is moved horizontally under the hot curve so as to reach the smallest vertical difference between the two curves $\Delta \mathrm{T}_{\min }$.

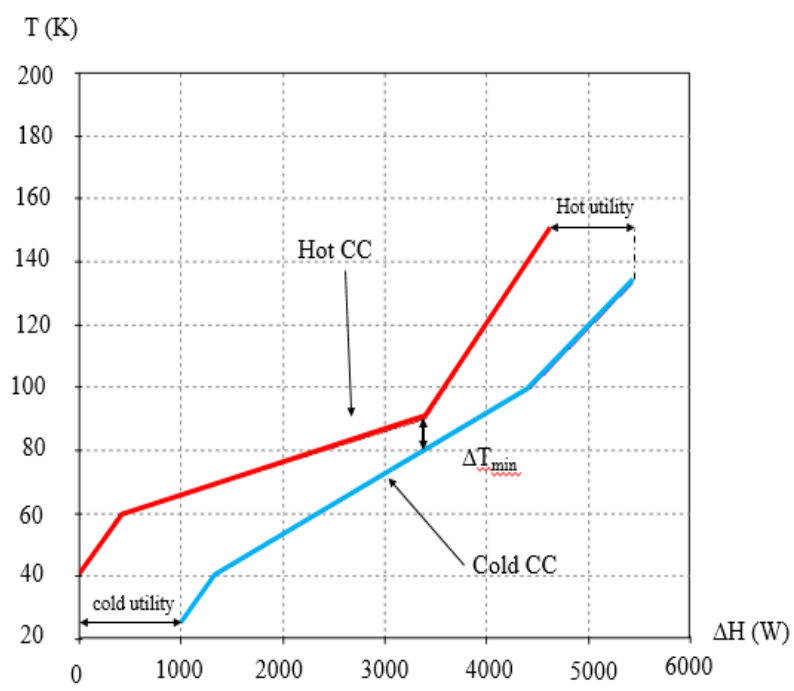

Fig. 3. Theoretical composites curves (CCs)

The $\Delta \mathrm{T}_{\min }$ is defined as the minimum temperature difference "allowed" (tolerable) or acceptable between the hot and cold streams of the process [18]. Several recommendations on how to choose the $\Delta \mathrm{T}_{\min }$ are classified in $[11,14,16]$. In our case, the $\Delta \mathrm{T}_{\min }=10^{\circ} \mathrm{C}$ will be chosen.

Generally in many processes, both hot and cold utilities are always required. However, this is not the case for all the problems; there are some situations called "threshold problems" where only one utility is required. The value of $\Delta \mathrm{T}_{\min }$ in which one utility target falls to zero is termed $\Delta \mathrm{T}_{\text {threshold. }}$ Threshold problems can be divided into two broad categories; in one type, there is an intermediate near-pinch or pseudo-pinch which can be identified from the composite curves as a region of close temperature approach. In the other type which corresponds to our case study, the closest temperature approach between the hot and cold composites is at the "non-utility end" and the curves diverge away from this point (fig. 4).

For $\Delta \mathrm{Tmin}=10^{\circ} \mathrm{C}$, the recovery area indicates the maximum heat recovery which is $80,27 \mathrm{~kW}$. The heat recovery is not possible in the region where the cold CC extends beyond the beginning of the hot $\mathrm{CC}$. To meet the energy balance, the external hot utility must be supplied and hence it should correspond to $316,99 \mathrm{~kW}$.

\subsection{The problem table algorithm (PTA) and the grand composite curve}

Even through the composite curves are useful to provide a conceptual understanding of the process, Linnhoff and Flower developed an algorithm known as Problem Table Algorithm (PTA). This numerical tool allows us to determine the pinch temperature of the building complex and its energy targets (minimum heating and cooling requirements).

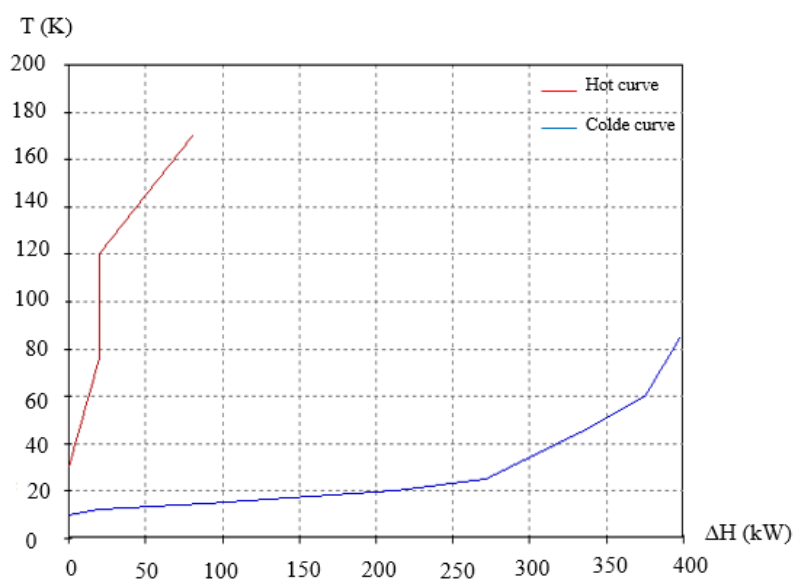

Fig. 3. Building complex composites curves (CCs)

To develop the PTA, the following steps are undertaken:

- Step 1: Set up the shifted temperature intervals The shifted temperatures of the streams are determined correspondingly with Eq. (1):

$$
T_{i}^{*}=T_{i}+\frac{\Delta T_{\min }}{2}
$$

Subtracting $\Delta \mathrm{T}_{\min } / 2$ from hot streams (Ti) and adding $\Delta \mathrm{T}_{\min } / 2$ to the cold streams (Ti).

- Step 2: compute the energy balance

In each shifted temperature interval, the values of the energy balance are calculated respectively in accordance with Eq. (2):

$$
\Delta H_{i}=\left(T_{i}^{*}-T_{i+1}^{*}\right)\left(\sum C_{p_{h}}-\sum C_{p_{c}}\right)_{i}
$$

Where:

$\Delta \mathrm{Hi}$ - the heat balance for the temperature interval $\mathrm{i}(\mathrm{kW})$. $\mathrm{Ti}^{*}$ - shifted by $1 / 2 \Delta \mathrm{Tmin}$ of the $\mathrm{i}$ interval.

$\mathrm{T} * \mathrm{i}+1$ - shifted by $1 / 2 \Delta \mathrm{Tmin}$ of the $\mathrm{i}+1$ interval.

$\sum \mathrm{Cp}_{\mathrm{h}}$ - the sum of thermal capacities of hot streams in the i interval $\left(\mathrm{kW} /{ }^{\circ} \mathrm{C}\right)$.

$\sum \mathrm{Cp}_{\mathrm{c}}$ - the sum of thermal capacities of cold streams in the $\mathrm{i}$ interval $\left(\mathrm{kW} /{ }^{\circ} \mathrm{C}\right)$.

\section{- $\quad$ Step 3: develop the heat cascade}

Heat cascade is based on a key feature of problem table algorithm that any heat available in interval $i$ is hot enough to supply its duty in interval $i+1$. Table 2 represents the Problem Table Algorithm; this table shows the thermodynamic data of the building system thermal balance realized with its hot and cold streams. 
The heat cascade columns (at stage 1 and 2) represent the sum of the thermal load realized from 0 and $|\Sigma \Delta \mathrm{Hi}|$ max respectively. It can be seen that the sum of the heat cascade at stage 1 column in all temperature intervals is not zero and the largest negative value found is $316,99 \mathrm{~kW}$ in the interval from 17 to $15^{\circ} \mathrm{C}$. In such a way, the pinch position which corresponds to $\Delta \mathrm{Tmin}=$ $10^{\circ} \mathrm{C}$ is found at 20 and $10{ }^{\circ} \mathrm{C}$ for the hot and cold curves respectively.

Furthermore, the amount of heat flowing from highest shifted interval temperature $\left(165^{\circ} \mathrm{C}\right)$ is $316,99 \mathrm{~kW}$. This heat goes to the hot utility. Thus, minimum hot utility demand is $316,99 \mathrm{~kW}$. Similarly, the amount of heat required to be supplied to the lowest shifted interval temperature $\left(15^{\circ} \mathrm{C}\right)$ in terms of cold utility is $0 \mathrm{~kW}$. This reflects the non-cold utility requirement.

The same results can be extracted from the grand composite curve (figure 5). The grand composite curve (GCC) is the tool used to identify the minimum consumption targets of utility. It is a curve generated from the composite curves and which illustrates, as a function of the temperature, the energy requirement (above the pinch point) for the threshold problem.

The GCC is the key answer for the minimum heat quantity that must be provided and its minimum temperature level (quality) to avoid its degradation with low efficiency. For the case study with the data of the PTA, the GCC is constructed. The temperature for which there is zero thermal need corresponds to the location of the pinch point $\left(\mathrm{Tpinch}=15^{\circ} \mathrm{C}\right.$ ). This curve confirms that the heating load theoretically required by the building complex is $316,99 \mathrm{~kW}$.

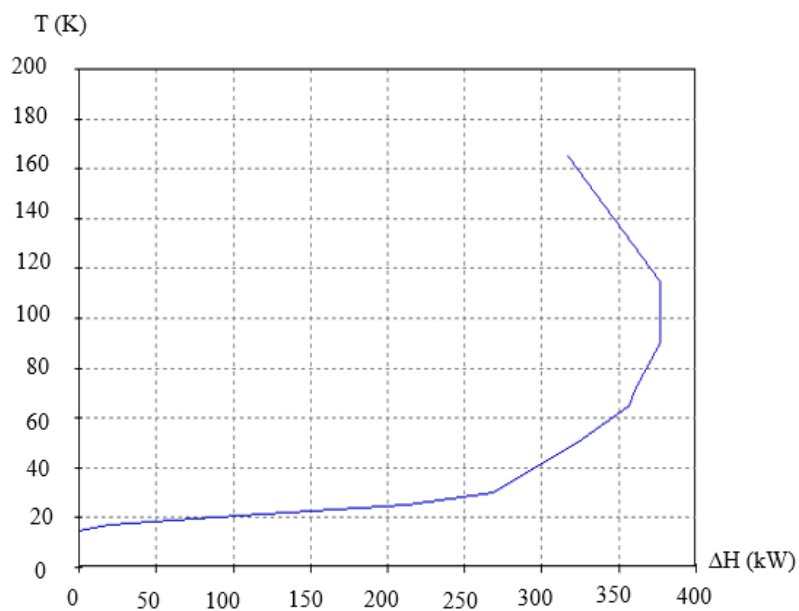

Fig. 5. Building complex grand composites curves

Table 1. Building complex PTA

\begin{tabular}{|c|c|c|c|c|c|c|c|c|c|c|c|c|c|}
\hline \multirow{2}{*}{$\mathrm{T}^{*}$} & \multicolumn{7}{|c|}{ Stream population } & \multirow{2}{*}{\multicolumn{4}{|c|}{\begin{tabular}{l|l|l|}
$\Delta \mathrm{T}^{*}$ & $\sum \mathrm{Cp}_{\mathrm{b}}-\sum \mathrm{C} \mathrm{p}_{\mathrm{c}}$ & \\
\end{tabular}}} & \multirow{3}{*}{$\begin{array}{c}\text { Heat cascade at } \\
\text { stage } 1\end{array}$} & \multirow{2}{*}{$\begin{array}{c}\begin{array}{c}\text { Heat cascade at } \\
\text { stage 2 }\end{array} \\
316.99\end{array}$} \\
\hline & BS & Soa & $\mathrm{L}$ & SW & $\mathrm{H}$ & SP & $\mathrm{BF}$ & & & & & & \\
\hline \multirow{2}{*}{165} & & & & & & & & & & & & & \\
\hline & & & & & & & & 50 & 1.2016 & 60.08 & D & 60.08 & 377.07 \\
\hline 115 & & & & & & & & 25 & 00.00 & 00.00 & & 60.08 & 377.07 \\
\hline \multirow[t]{2}{*}{90} & & & 4 & & & & & & & & & & \\
\hline & & & & & & & & 19 & -0.8973 & -17.05 & $\mathrm{~S}$ & 43.03 & 360.02 \\
\hline 71 & & & & & & & & 6 & -0.4583 & -2.75 & $\mathrm{~S}$ & 40.28 & 357.27 \\
\hline 65 & & & & & & & & 15 & -2.3474 & -35.211 & $\mathrm{~S}$ & 5.069 & 322.06 \\
\hline \multirow[t]{2}{*}{50} & & & & & & & 4 & & & & & & \\
\hline & & & & & & & & 20 & -2.6374 & -52.748 & $\mathrm{~S}$ & -47.679 & 269.31 \\
\hline 30 & & & & & & 4 & & 5 & -11.3708 & -56.854 & S & -104.533 & 212.45 \\
\hline \multirow[t]{2}{*}{25} & & $\gamma$ & & & & & & & & & & & \\
\hline & & & & & & & & 5 & -24.7847 & -123.924 & S & -222.457 & 88.53 \\
\hline 20 & & & & & & & & 3 & -22.8958 & -68.6874 & $\mathrm{~S}$ & -297.144 & 19.84 \\
\hline 17 & & & & & & & & 2 & -9.9208 & -19.8416 & $\mathrm{~S}$ & -316.99 & 00.00 \\
\hline 15 & & & & & & & & & & & & & \\
\hline
\end{tabular}




\subsection{Heat exchanger network (HEN)}

Improving a heat exchanger network by using the pinch method requires a diagram representation that shows the position of the pinch point and the distribution of streams. In addition, this diagram must be manipulated in order to establish the connections between the hot and cold streams. In this context, B. Linnhoff and J.R. Flower [17] proposed a grid diagram; the idea is to draw the hot and cold streams in counter-current by directing them from their starting temperatures to their targeted temperatures. To achieve the design of an exchanger network with a minimum consumption, B. Linnhoff and E. Hindmarsh reported that it is imperative to respect the following three basic rules of pinch analysis [18]:

- Don't transfer heat across the pinch.

- Don't use cold utilities above the pinch.

- Don't use hot utilities below the pinch.

Based on the data building complex (table 1), the golden rules of pinch analysis and the feasibility rules, the heat exchanger network is shown in fig. 6 :

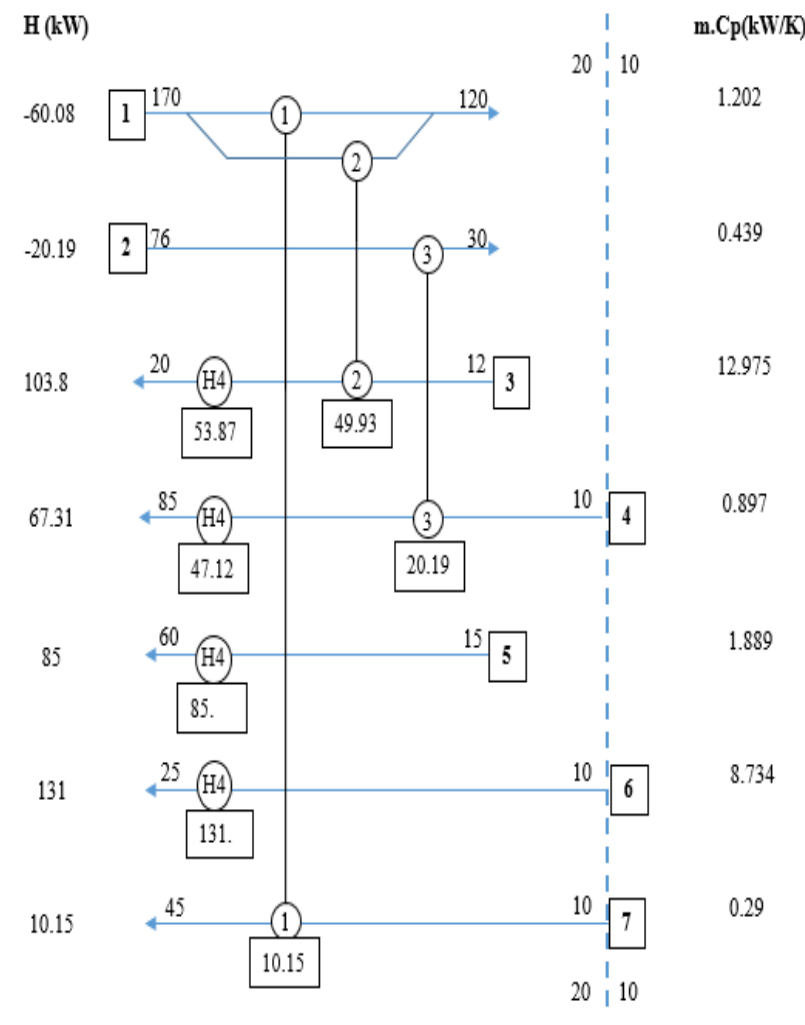

Fig. 6. Building complex heat exchange network

The diagram is organized according to the horizontal temperature scale with a vertical intermediate dashed line that locates the hot and cold pinch temperature (20 and $10^{\circ} \mathrm{C}$ respectively). The supply and target temperatures are mentioned above each flow vectors. Interconnected circles indicate the heat exchangers and the circles indicate the utility exchangers. The rectangles indicate the numbering of the flows and the thermal load exchanged between streams. The left and right ends respectively indicate the quantity of energy that must be supplied or acquired and the heat flow rate.

\section{Results and discussion}

During the evaluation of the opportunities to integrate processes into the building complex system, we assumed that the heating demand reached $397,26 \mathrm{~kW}$. Taking into account the flow of the boiler's condensed smoke as well as the wasted heat from the soapy water of the laundry, the heating demand can be decreased to $316,99 \mathrm{~kW}$. Fig. 6 shows the heat exchanger network design for the building complex. Based on the feasibility rules, the detail engineering and implementation, the pinch analysis suggests to place three heat exchangers to achieve this energy saving potential. The design of HEN is relatively complex because it has 3 additional heat exchangers. The aim behind the addition of heat exchangers is actually to ensure the maximum heat recovery via the streams interchanges compared to the initial situation where some streams with significant energy potential is wasted.

Referring to the grid diagram, two waste heat streams are used; the hot stream number 1 (boiler smoke) is able to heat the stream number 7 (boiler feed water) and bring its temperature to the one conditioned at the entrance of the boiler $\left(45^{\circ} \mathrm{C}\right.$ instead of $\left.10{ }^{\circ} \mathrm{C}\right)$ and simultaneously preheat stream number 3 (heating) by $49,93 \mathrm{~kW}$ from temperature $12{ }^{\circ} \mathrm{C}$ to $15^{\circ} \mathrm{C}$. The soapy water (stream 2) which comes out at $76{ }^{\circ} \mathrm{C}$ preheats stream 4 (for the Laundry) from $10{ }^{\circ} \mathrm{C}$ to $32{ }^{\circ} \mathrm{C}$ and $47,12 \mathrm{~kW}$ of utility is added in order to increase its temperature to $85^{\circ} \mathrm{C}$. After energy integration, the overall thermal demand of the building complex is $316,99 \mathrm{~kW}$.

The new heat exchanger network and implementation of new heat exchangers is feasible since the hot and cold flows are located in the same place (technical room and central laundry room). The identification of the optimum heat exchanger network design which is under investigation will be the second part of this work. Throughout this part, the exploration of the data analysis of the heat exchangers as well as their optimization will be carried out. Nevertheless, the proposed heat exchanger network design allows to perceive the potential recovered. As demonstrated by these results, the Pinch method applied to integrate the process to building can provide more efficient solutions for building complex, buildingtertiary and to promote them in future.

\section{Conclusion}

This paper deals with the energy saving strategy in a building complex. According to the pinch method which is a technology able to resolve real problems in terms of energy efficiency, the maximum thermal energy required to satisfy all the heating demand in the building complex is $316,99 \mathrm{~kW}$. Initially, the thermal energy demand to satisfy all requirements was $397,26 \mathrm{~kW}$. After energy integration, $21,16 \%$ of energy has been saved through three additional heat exchangers.

The results presented in this work indicate that energy integration provides considerable reduction in energy consumption. Thanks to this, economic and environmental benefits are gained from the reduction of fuel oil consumption as well as the reduction of gas 
emissions. As indicated by the grand composite curve, the building complex is a low thermal energy system. This means that an important part of thermal energy demand can be satisfied through heat pumps and more solar collectors which are considered as compatible energy technologies.

\section{References}

1. C. O. Holliday, «Sustaining human life through sustainable energy », Energy Strategy Rev., vol. 2, no 3-4, p. 209-210, févr. 2014.

2. MAEE, Moroccan Agency for Energy Efficiency. http://www .amee.ma/index.php?option=com_conten $\mathrm{t} \&$ view $=$ article $\& \mathrm{id}=125 \&$ Itemid=174\&lang=en (last accessed 20 August 2020).

3. MIITDE, Ministry of Industry, Investment, Trade and Digital Economy. http://www.mcinet.gov.ma /en/content/renewable-energy (last accessed August 2020)

4. O. Edenhofer, R. Pichs-Madruga, Y. Sokona. IPCC, the Intergovern-mental Panel on Climate Change, Special Report on Renewable Energy Sources and Climate Change Mitigation 2012.

5. MAEE, Maroccan Agency for Energy Efficiency Energy efficiency in building. https://www.amee.ma len/node/118 (last accessed August 2020)

6. D. D'Agostino, F. de' Rossi, M. Marigliano, C. Marino, et F. Minichiello, «Evaluation of the optimal thermal insulation thickness for an office building in different climates by means of the basic and modified "cost-optimal" methodology », J. Build. Eng., vol. 24, p. 100743, juill. 2019.

7. M. Jerman, I. Palomar, V. Kočí, Et R. Černý, «Thermal And Hygric Properties Of Biomaterials Suitable For Interior Thermal Insulation Systems In Historical And Traditional Buildings », Build. Environ., Vol. 154, P. 81-88, Mai 2019.

8. E. M. E. Khattabi, M. Mharzi, M. Zouini et K. Valancius, «Comparative Study of Various Thermal Analyses of Smart Windows in Cubic Building Design », JESTR, vol. 11, no 5, p. 86-92, oct. 2018

9. B. Linnhoff et J. R. Flower, « Synthesis of heat exchanger networks: I. Systematic generation of energy optimal networks », AIChE J., vol. 24, no 4, p. 633-642, juill. 1978.

10. D. W. Townsend et B. Linnhoff, « Heat and power networks in process design. Part I: Criteria for placement of heat engines and heat pumps in process networks », AIChE J., vol. 29, no 5, p. 742-748, sept. 1983.

11. I. C. Kemp, Pinch analysis and process integration: a user guide on process integration for the efficient use of energy, 2nd ed. Amsterdam ; Boston: ButterworthHeinemann, 2007.

12. Klemeš, Varbanov, Wan Alwi, Manan, « Process Integration and Intensification: Saving Energy, Water and Resources », p. 269.
13. A. Bertrand, R. Aggoune, et F. Maréchal, « Inbuilding waste water heat recovery: An urban-scale method for the characterisation of water streams and the assessment of energy savings and costs », Appl. Energy, vol. 192, p. 110-125, avr. 2017.

14. A. Herrera, J. Islas, A. Arriola, « Pinch technology application in a hospital », Applied Thermal Engineering, vol. 23, p. 127-139. 2003.

15. V. misevičiūtè, V. motuzienè, K. valančius, « the application of the pinch method for the analysis of the heat exchangers network in a ventilation system of a building », applied thermal engineering, vol 129, p. 772-781, january 2018.

16. Ressources Cannada, Pinch Analysis: for the Efficient Use of Energy, Water and Hydrogen http://publications.gc.ca/collections/collection_2012 /rncan-nrcan/M39-96-2003-fra.pdf

17. M. Bennajah, N. Chaouni. Echangeurs de Chaleur: Technologie, calcul et design. Edition TECHNIP, 1 rue du Bac, 75007 Paris, 2014.

18. B. Linnhoff, E. Hindmarch, " the pinch design method for heat exchanger networks », Chemical Engineering Science, vol. 38, No. 5, p. 745-763, 1983 